\title{
Sequential Processing of Cold Gas Sprayed Alloys by Milling and Deep Rolling
}

\author{
Daniel Meyer ${ }^{1,2}\left(\mathbb{D}\right.$, Lars Schönemann ${ }^{1,2}\left(\mathbb{D}\right.$, Nicole Mensching ${ }^{1, *} \mathbb{(}$, Volker Uhlenwinkel ${ }^{1,2}(\mathbb{D})$ \\ and Bernhard Karpuschewski 1,2 (D) \\ 1 University of Bremen and MAPEX Center for Materials and Processes, Bibliothek Str. 1, \\ 28359 Bremen, Germany; dmeyer@iwt-bremen.de (D.M.); schoenemann@iwt.uni-bremen.de (L.S.); \\ uhl@iwt.uni-bremen.de (V.U.); karpuschewski@iwt-bremen.de (B.K.) \\ 2 IWT Leibniz Institute for Materials Engineering, Badgasteiner Str. 3, 28359 Bremen, Germany \\ * Correspondence: mensching@iwt-bremen.de; Tel.: +49-421-218-51132
}

check for updates

Citation: Meyer, D.; Schönemann, L.; Mensching, N.; Uhlenwinkel, V.; Karpuschewski, B. Sequential Processing of Cold Gas Sprayed Alloys by Milling and Deep Rolling. Materials 2021, 14, 3699. https:// doi.org/10.3390/ma14133699

Academic Editor: Grzegorz Królczyk

Received: 27 May 2021

Accepted: 29 June 2021

Published: 1 July 2021

Publisher's Note: MDPI stays neutral with regard to jurisdictional claims in published maps and institutional affiliations.

Copyright: (c) 2021 by the authors. Licensee MDPI, Basel, Switzerland. This article is an open access article distributed under the terms and conditions of the Creative Commons Attribution (CC BY) license (https:/ / creativecommons.org/licenses/by/ $4.0 /)$.

\begin{abstract}
Cold gas spraying (CS) is a solid-state material deposition process which, in addition to the flexible repair of individual component areas, also enables the build-up of larger samples. The layers are created on a substrate by the impact-induced bonding of highly accelerated micrometer particles. Since melting does not occur, the material composition can be varied flexibly and independently of material-specific melting points. In this work, the influence of the described forming process on subsequent machining by milling and deep rolling is investigated. The process forces measured during milling and the surface topography after milling and deep rolling were influenced by the material composition and the CS-related properties, e.g., high material hardness or particle bonding. In contrast to prior assumptions, deep rolling was shown to have no influence on the determined hardness depth profile for the investigated materials. Future work will focus on additional analyses, such as the determination of half-widths, to obtain further insight on the material behavior.
\end{abstract}

Keywords: cold gas spraying; deep rolling; milling; plastic deformation; surface properties

\section{Introduction}

The possibility of fast and application-oriented manufacturing of highly complex components has led to the increased importance of Additive Manufacturing (AM) processes in multiple industrial sectors, such as medical technology or aerospace [1]. By offering new design options, AM enables near-net-shape production and, thus, a weight-reduced component design [2]. Various AM techniques such as Laser Powder Bed Fusion (LPBF) or Laser Metal Deposition (LMD) have been developed within recent years and are applied to generate parts made of metal, polymers, and composites in a layer-based way [3]. Most AM processes involve the melting of the material during the generation of the component, which results in high temperature gradients and complex residual stress distributions [4]. Crack formation, material oxidation, or undesired phase transformation may occur. During the melting process, the properties and composition of the supplied powder are changed in laser-based AM.

Within this work, three different cold gas sprayed (CS) alloys are investigated (316L, FeTiB and FeMnAlC). CS is a method originally developed as a coating technology [5,6] and is increasingly gaining importance in the field of additive manufacturing [7]. It involves a low-temperature gas jet accelerating particles with micrometer-scale sizes (powders) accumulating into dense coatings due to severe plastic deformation when impacting on a substrate [8-10]. According to Yin et al., this severe plastic deformation is the basic requirement for intermixing at the substrate-coating interface, which influences the adhesion of the coating [11]. Depending on the process design, a distinction is made between high-pressure cold spray and low-pressure cold spray, resulting in lower or higher particle velocities, respectively [7]. According to the review of Rokni et al., the extent of particle 
deformation and, thereby, also the deposition efficiency is influenced by the particle temperature and particle velocity [7]. The particle velocity needs to exceed a critical velocity to adhere on the substrate [12]. This critical velocity is influenced not only by the material of the particle and the substrate but also by, e.g., the processing parameters, the particle size and the topological properties of the substrate surface [13]. Since the particles bond due to their kinetic energy, no powder melting and, thus, evaporation-related changes of the alloying composition usually occur [13]. Thus, CS is suitable for temperature-sensitive or oxygen-sensitive materials [14,15]. Furthermore, it allows the combination of different materials already in powder form, which, as shown by AL-Mangour et al. using 316L and $\mathrm{Co}-\mathrm{Cr}$, not only improves tensile strength but also corrosion properties compared to pure stainless steel [16]. Considering the microstructure, the large strains (up to 10) and strain rates (up to $10^{9} \mathrm{~s}^{-1}$ ) lead to work hardening, which, together with the severe plastic deformation, temperature increase, and intense shear stress, in turn leads to grain refinement by dynamic restoration phenomena (dynamic recovery and dynamic recrystallization) at the particle-substrate and particle-particle interfaces $[7,17]$. According to Ogawa et al., the intense particle deformation during CS can further lead to a loss of ductility [18], which can be improved, for example, by post-CS heat treatment [7].

Regardless of the applied coating or AM process, the generated parts usually show drawbacks such as lower tensile strength, porosity or a high surface roughness, which in most applications requires additional post-processing by, e.g., heat treatment $[7,16]$, hot isostatic pressing (HIP), milling or turning. In some cases, the cutting process is followed by a mechanical surface treatment [19] such as deep rolling, shot peening [20] or machine hammer peening [21] to further improve the surface roughness and to introduce strain hardening as well as compressive residual stresses [22]. Although these processes lead to an extension of the process chain, they are generally accompanied by an improvement in fatigue strength and, therefore, an extended component lifetime [23-25].

This has been investigated for LPBF components, for example by Breidenstein et al., who performed experiments on the influence of milling and deep rolling on the Surface Integrity of H13-steel-parts [22]. Meyer and Wielki also investigated the potential of deep rolling as a finishing process of AM steel parts and showed that improvements in surface roughness and subsurface properties are possible even without an intermediate cutting process $[26,27]$. However, corresponding investigations for CS samples have not yet been carried out systematically.

In this work, three cold gas sprayed alloys (316L, FeTiB and FeMnAlC; coating thickness $>2 \mathrm{~mm}$ ) are post-processed by milling and/or deep rolling to develop procedures for the post-processing of future standalone parts (detached from the substrate) based on the analyzed surface and subsurface properties. While $316 \mathrm{~L}$ is a commercially available and established alloy, the other two alloys have not yet been considered in the CS process. With the aim of a rapid usability of the new powders, a time-consuming parameter study is deliberately dispensed with and the potential of deep rolling to overcome the drawbacks of non-optimized CS parameters is investigated. Both the as-sprayed surface as well as the processed surfaces are investigated. By varying the process parameters, the machinability of the cold gas sprayed alloys is assessed. Furthermore, the influence of the processing steps on the subsurface properties is investigated by aid of micrographs, hardness depth profiles, and EBSD measurements. Aiming at the mentioned compensation of drawbacks due to the parameter settings not being material-adjusted, the aim of the current work is to find out to what extent the plastic deformation associated with the CS can be further influenced by deep rolling.

\section{Materials and Methods}

\subsection{Cold Gas Sprayed Coatings}

Within this work, cold gas spraying of three steel alloys (316L, FeTiB and FeMnAlC) was investigated. Samples were generated by an Impact Spray System 5/11 (Impact Innovations $\mathrm{GmbH}$, Rattenkirchen, Germany) at the test center of the manufacturer. The 
chemical composition of the particles can be found in Table 1. While the 316L powder is commercially available (supplier: Sandvik, Sandviken, Schweden, cf. [28]) and widely applied in $\mathrm{AM}$, the FeMnAlC and the FeTiB powder was generated by inert gas atomization at the Leibniz Institute for Materials Engineering (Bremen, Germany).

Table 1. Chemical composition in WT\% of particles utilized for cold spraying $\left({ }^{1}\right.$ according to [28]; ${ }^{2}$ according to in house measurements, cf. [29]).

\begin{tabular}{ccccccccccccc}
\hline & Fe & Mn & Al & C & Ti & B & Si & P & S & Cr & Ni & Mo \\
\hline $316 L^{1}$ & $62-68$ & $\leq 2$ & 0 & $\leq 0.03$ & 0 & 0 & $\leq 1$ & $\leq 0.045$ & $\leq 0.03$ & $16-18$ & $10-14$ & $2-3$ \\
FeTiB $^{2}$ & 82.4 & 0 & 0 & 0 & 5.6 & 12.0 & 0 & 0 & 0 & 0 & 0 & 0 \\
FeMnAlC $^{2}$ & 59.1 & 32.7 & 4.6 & 3.6 & 0 & 0 & 0 & 0 & 0 & 0 & 0 & 0 \\
\hline
\end{tabular}

Cold spraying was performed using aluminum and steel substrates (size: $5 \mathrm{~mm}$ $\times 50 \mathrm{~mm} \times 30 \mathrm{~mm}$ ). While the aluminum substrates were cleaned using ethanol, the steel substrates were sand blasted before cold gas spraying. Table 2 summarizes the cold gas spraying parameters. It has to be noted that these parameters have been selected according to the recommendations of the aforementioned producer of the spray system and are optimized for spraying 316L. Due to the limited experience in cold spraying FeTiB and FeMnAlC, the settings may not yet be optimal for these alloys. As a consequence, the deposition efficiency of the coatings varies from approx. $94.9 \%$ for $316 \mathrm{~L}$ to $77.6 \%$ for FeMnAlC and $18.7 \%$ for FeTiB. The thickness of the material layered by means of cold gas spraying is $2.1 \mathrm{~mm}$ for 316L, $2 \mathrm{~mm}$ for FeMnAlC and $2.5 \mathrm{~mm}$ for FeTiB.

Table 2. Cold gas spraying parameters.

\begin{tabular}{ccc}
\hline Process gas & $\mathrm{N}_{2}$ \\
Gas pressure & $50 \mathrm{bar}$ \\
Gas temperature & $100{ }^{\circ} \mathrm{C}$ \\
Standoff distance & $30 \mathrm{~mm}$ \\
Gun travel speed & $250 \mathrm{~mm} / \mathrm{s}$ \\
Step distance & $1 \mathrm{~mm}$ \\
Feeding rate & $2 \mathrm{~kg} / \mathrm{h}$ \\
Nozzle path & Zigzag & \\
Layers & T16L and FeMnAlC: & 6 \\
& FeTiB: & 25 or 30 \\
Particle size & 316L: & $15-38 \mu \mathrm{m}$ \\
& FeTiB: & $15-40 \mu \mathrm{m}$ \\
& FeMnAlC: & $15-40 \mu \mathrm{m}$ \\
\hline
\end{tabular}

With a gas flow of $4 \mathrm{~m}^{3} / \mathrm{h}$, a disc speed of $3 \mathrm{rpm}$ (disc type: 120) and an open bypass, powder was supplied through the first powder feeder. The second powder feeder was used for cooling (water: $10^{\circ} \mathrm{C}$ ).

\subsection{Post Processing}

\subsubsection{Milling}

The machinability of the cold sprayed samples in an as-sprayed state was analyzed by milling individual tracks and determining the cutting forces. Milling experiments were performed on an Ultrasonic 20 linear milling machine (DMG Mori, Bielefeld, Germany).

Figure 1 shows the experimental setup. A toroidal cutter with a diameter of $\mathrm{D}=12 \mathrm{~mm}$, six teeth $\left(z_{t}=6\right)$, and a corner radius of $r_{c}=0.5 \mathrm{~mm}$ was used. While the spindle speed $\mathrm{n}\left(8000 \mathrm{~min}^{-1}\right)$, the cutting speed $\mathrm{v}_{\mathrm{c}}\left(302 \mathrm{~m} \cdot \mathrm{min}^{-1}\right)$, the depth of cut $\mathrm{a}_{\mathrm{p}}(1 \mathrm{~mm})$, and the width of cut $a_{e}(0.6 \mathrm{~mm})$ were kept constant, the feed velocity $v_{f}$ was varied between $2800 \mathrm{~mm} \cdot \mathrm{min}^{-1}$ and $4600 \mathrm{~mm} \cdot \mathrm{min}^{-1}$ in steps of $200 \mathrm{~mm} \cdot \mathrm{min}^{-1}$, i.e., with a feed per tooth of $\mathrm{f}_{\mathrm{z}} \approx 58.3 \mu \mathrm{m}$ to $95.8 \mu \mathrm{m}$ in steps of $4.2 \mu \mathrm{m}$. Experiments were repeated 3 times for a basic assessment of reproducibility. Cutting forces were measured utilizing a piezoelec- 
tric 3-component dynamometer (Typ 9256C 2, Kistler Instrumente GmbH, Sindelfingen, Germany) with a sampling rate of $30 \mathrm{kHz}$. Within this work, the active force $\mathrm{F}_{\mathrm{a}}$ of the $\mathrm{X}$ and $\mathrm{Y}$ force components $\left(\mathrm{F}_{\mathrm{x}}, \mathrm{F}_{\mathrm{y}}\right)$ was calculated and used as the basis for all comparisons (Equation (1)):

$$
\mathrm{F}_{\mathrm{a}}=\sqrt{\mathrm{F}_{\mathrm{x}}^{2}+\mathrm{F}_{\mathrm{y}}^{2}}
$$

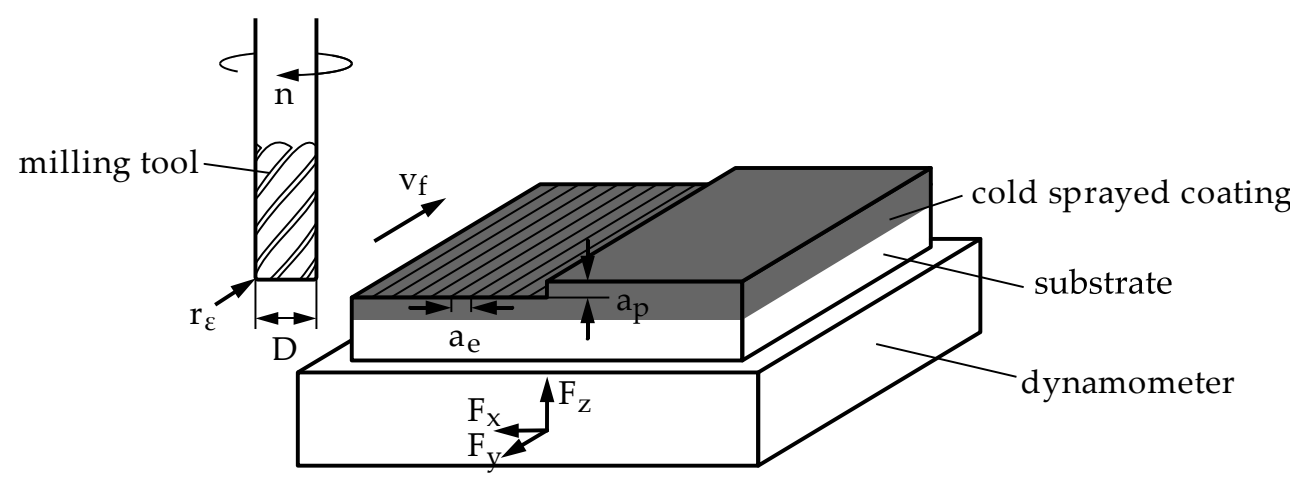

Figure 1. Experimental setup for the milling experiments.

For each experiment, the mean of $\mathrm{F}_{\mathrm{a}}$ and the standard deviation of the mean $\mathrm{s}_{\mathrm{Fa}}$ was determined by averaging the peak force values during stable cutting conditions, which occur at a frequency of $\mathrm{f}_{\text {peak }}=\mathrm{n} / 60 \cdot \mathrm{z}_{\mathrm{t}}=800 \mathrm{~Hz}$. Thereafter, the results of all three experiments were merged by calculating the weighted mean and its error.

For surface analysis, the Keyence digital microscope VHX-S 15 (KEYENCE DEUTSCHLAND GmbH, Neu-Isenburg, Germany) and the coherence scanning interferometer Talysurf CCI HD (AMETEK GmbH, BU Taylor Hobson, Weiterstadt, Germany) were used, enabling high resolution imaging as well as the three-dimensional profile measurements of structures and surfaces in the range of a few micrometers.

\subsubsection{Deep Rolling}

Deep rolling experiments were performed on a 3-axis CNC machining center (DMC $65 \mathrm{~V}$ by Deckel Maho, Pfronten, Germany) utilizing a hydrostatic deep rolling tool with a spherical ceramic tip (diameter: $6 \mathrm{~mm}$ ) Ecoroll HG6 (Ecoroll AG Werkzeugtechnik, Celle, Germany). The experimental setup is shown in Figure 2.

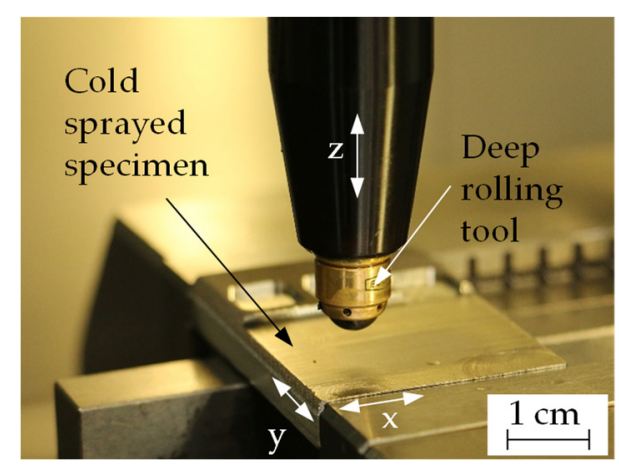

Figure 2. Experimental setup for deep rolling.

Table 3 lists the process parameters applied in the deep rolling experiments. The deep rolling force $\mathrm{F}_{\mathrm{r}}$ was measured utilizing a piezoelectric 3-component dynamometer (Typ 9257 B, Kistler Instrumente $\mathrm{GmbH}$, Sindelfingen, Germany) equipped by a Kistler charge amplifier Typ 5019 A (low pass filter: $500 \mathrm{~Hz}$; sampling rate: $2500 \mathrm{~Hz}$ ). 
Table 3. Process parameter of the deep rolling process.

\begin{tabular}{|c|c|c|c|}
\hline Component & & Values & \\
\hline Tool diameter $\mathrm{d}_{\mathrm{b}}(\mathrm{mm})$ & & 6 (HG 6) & \\
\hline Deep rolling pressure $\mathrm{p}_{\mathrm{r}}(\mathrm{bar})$ & 100 & 200 & 400 \\
\hline Measured rolling Force $\mathrm{F}_{\mathrm{r}}(\mathrm{N})$ & $240 \pm 5$ & $492 \pm 9$ & $996 \pm 13$ \\
\hline Step over $\mathrm{s}_{\mathrm{o}}(\mathrm{mm})$ & & 0.1 & \\
\hline Rolling speed $\mathrm{v}_{\mathrm{r}}(\mathrm{mm} / \mathrm{min})$ & & 100 & \\
\hline Lubricant & & 8\%-emulsion & \\
\hline Size of deep rolled area $\left(\mathrm{mm}^{2}\right)$ & & varied $\geq 7 \times 7$ & \\
\hline
\end{tabular}

Furthermore, cross-sections of the processed areas were generated to gain further insights about the microstructure of the investigated cold gas sprayed samples and the influence of the applied post-processing strategies on the microstructure. For selected samples, these are supported by hardness depth profiles. Figure 3 shows an overview of the experiments performed on each sample.

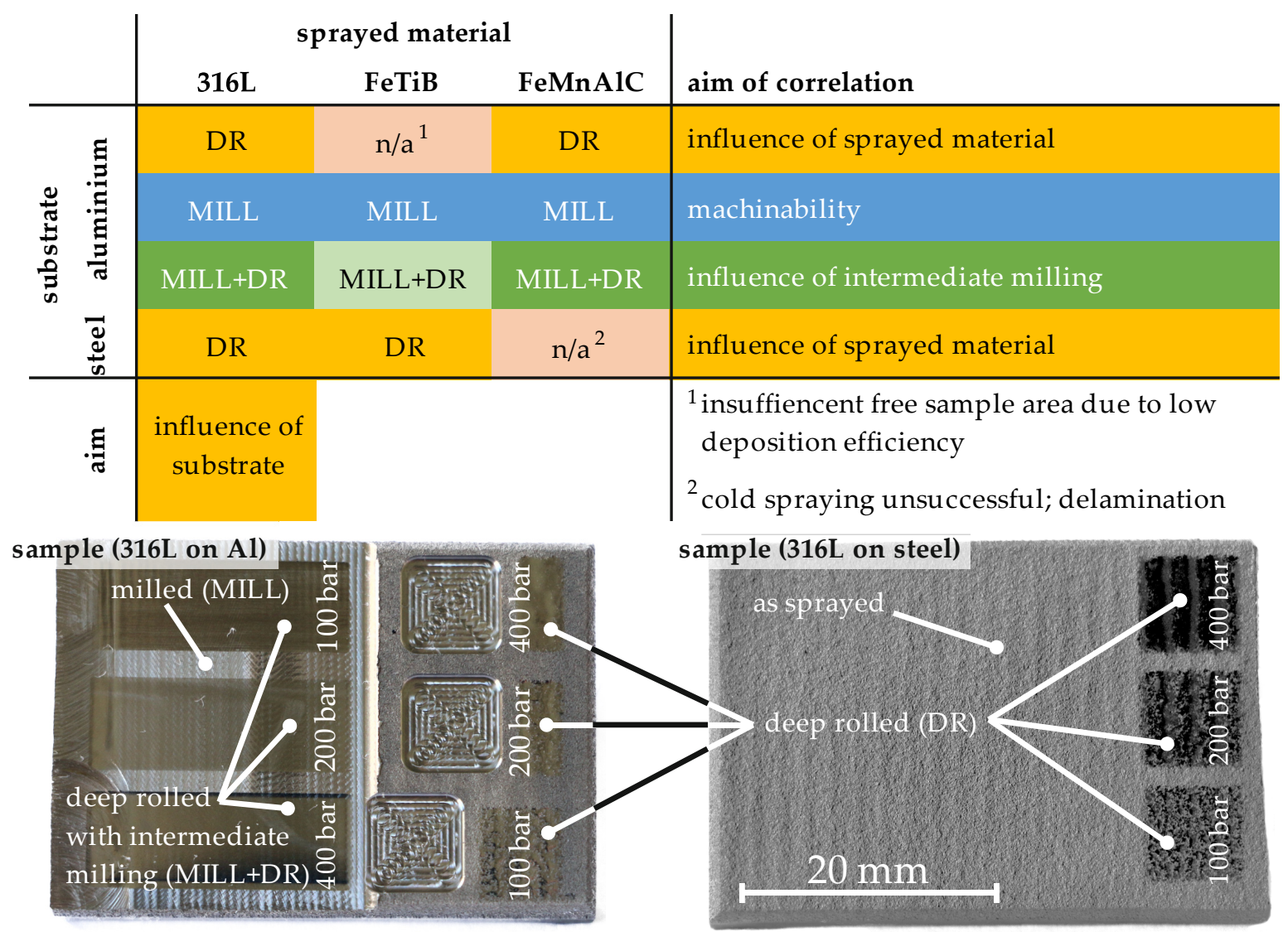

Figure 3. Schematic illustration of the experimental procedure.

\subsection{Further Devices}

The hardness values discussed in this paper were determined in conformity with the standard according to Rockwell (HRC) with a cone-shaped diamond indenter and according to Vickers with an equal-sided diamond pyramid indenter. EBSD measurements were performed on a Helios G4 PFIB CXe (Thermo Fisher Scientific, 168 Third Avenue Waltham, MA USA 02451). With increments of $0.1 \mu \mathrm{m}$, measuring fields of a size of $50 \times 100 \mu \mathrm{m}^{2}$ were acquired (voltage: $20 \mathrm{kV}$, current: $6.4 \mathrm{nA}$ ). The image quality (IQ), the inverse pole figure (IPF), and the Kernel Average Misorientation (KAM) were determined. 


\section{Results}

In this section, the initial state of the alloys after cold spraying is presented first. For a direct comparison, in addition to the micrographs shown, hardness measurements according to Rockwell were carried out. The results of the experimental program are first presented for the milling process. These are followed by the results obtained after deep rolling with different deep rolling pressures with and without intermediate milling.

\subsection{Inital State of CS Coatings}

While 316L and FeTiB exhibited a good bonding behavior in both cases, usable coatings with FeMnAlC could only be generated on the aluminum substrate. The hardness of the applied coatings was measured to $34 \mathrm{HRC}$ for 316L, $37 \mathrm{HRC}$ for FeMnAlC, and $52 \mathrm{HRC}$ for FeTiB. Figure 4 shows the microstructure of the as-sprayed surface. Cross-sections were etched for $15 \mathrm{~s}(\mathrm{FeTiB})$ or $20 \mathrm{~s}$ (FeMnAlC) using 3\% alcoholic $\mathrm{HNO}_{3}$ and for $30 \mathrm{~s}$ using $60 \%$ electrolytic etchant. The high surface roughness directly after cold gas spraying becomes obvious in the micrographs. Individual bonded particles can be identified and pores are visible for FeTiB and FeMnAlC.

a) $316 \mathrm{~L}$

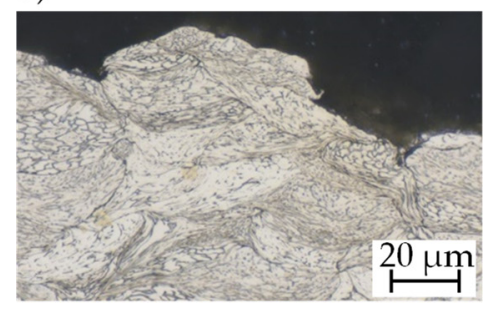

b) $\mathrm{FeTiB}$

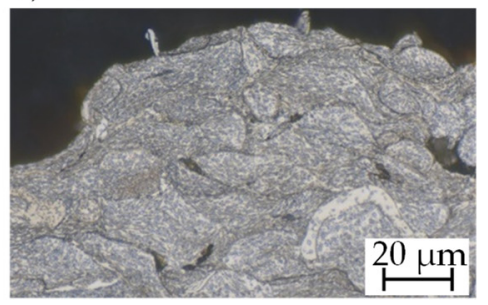

c) FeMnAlC

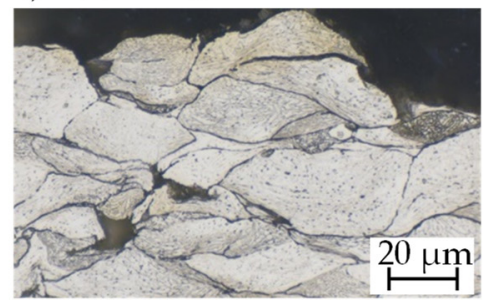

Figure 4. Microstructure of the cold sprayed samples: (a) etched $20 \mathrm{~s}$ in $60 \%$ electrolytic $\mathrm{HNO}_{3}(1.5 \mathrm{~V})$; (b,c) etched 15-20 s in $3 \%$ alcoholic $\mathrm{HNO}_{3}$.

\subsection{Milling}

To evaluate the machinability of the cold-sprayed samples, measurements of the cutting forces during milling were performed. Figure 5 shows the active force $F_{a}$ plotted over the feed velocity $v_{f}$ for each material. A systematic error is present for the initial values $\left(v_{f}=2800 \mathrm{~mm} / \mathrm{min}\right)$ for FeTiB and FeMnAlC, which is indicated by a large (external) error. In these two cases, the three repetitions of the experiment were consistent within themselves (low internal error), but did not yield similar force levels. This may be attributed to unequal cutting conditions, as this was the first cut into the substrate. The cutting strategy was changed for 316L, which therefore shows no systematic error for the initial run. As the feed rate increases, the active force increases for all materials, as can be expected, and a (weighted) linear fit of the progression yields high determination coefficients if outliers are disregarded $\left(v_{f}=2800 \mathrm{~mm} / \mathrm{min}\right.$ for FeMnAlC and FeTiB and $\mathrm{v}_{\mathrm{f}}>4000 \mathrm{~mm} / \mathrm{min}$ for 316L). The active forces for 316 $\mathrm{L}$ are lower than those of the other materials for all parameters. The active force for FeMnAlC starts at a medium level around $150 \mathrm{~N}$ but shows the strongest increase thereafter (max. value: $\mathrm{F}_{\mathrm{a}} \approx 232.5 \mathrm{~N}$ at $\mathrm{v}_{\mathrm{f}}=3600 \mathrm{~mm} \cdot \mathrm{min}^{-1}$ ). This increase was so significant that the experiments had to be stopped because the selected measurement range of the dynamometer (0-250 N per channel) was exceeded. Active forces for cutting FeTiB start at the highest initial value of all alloys $\left(\mathrm{F}_{\mathrm{a}} \approx 178.5 \mathrm{~N}\right.$ at $\mathrm{v}_{\mathrm{f}}=3000 \mathrm{~mm} / \mathrm{min}$, resp. $\mathrm{F}_{\mathrm{a}} \approx 245 \mathrm{~N}$ at $\mathrm{v}_{\mathrm{f}}=2800 \mathrm{~mm} / \mathrm{min}$, which is considered as an outlier), but only gradually increase with feed velocity (max. value: $\mathrm{F}_{\mathrm{a}} \approx 220 \mathrm{~N}$ at $\mathrm{v}_{\mathrm{f}}=4800 \mathrm{~mm} / \mathrm{min}$ ). A correlation between hardness and resultant forces cannot be drawn. For instance, FeMnAlC shows a totally different initial offset and progression to 316L, although it is of similar hardness. This may partly be attributed to the progression of tool wear during cutting. In the experiments, FeTiB and FeMnAlC were machined using the same milling tool, which showed no visible tool wear after the FeTiB. This conforms to the almost linear progression of the active forces. The machining of FeMnAlC caused significant tool wear, which led to the experiments 
being stopped prematurely. This results in a low determination coefficient for the linear fit. One explanation of the increased wear could be attributed to oxides that have formed due to the high temperatures in the cold spraying processes (indicated by annealing colors of the coating after spraying). However, this cannot be verified with the given experiments as FeMnAlC without annealing is not available for comparison. The $316 \mathrm{~L}$ alloy was then machined using an unused tool. It shows a linear progression up to $\mathrm{v}_{\mathrm{f}}=4000 \mathrm{~mm} / \mathrm{min}$ with a disproportionate increase thereafter. Forces rise from approx. $60 \mathrm{~N}$ to $190 \mathrm{~N}$.

Process: slot milling of cold sprayed samples

Tool: torodial miller, $\mathrm{t}=6, \mathrm{D}=12 \mathrm{~mm}, \mathrm{re}=0.5 \mathrm{~mm}$

Parameters: $\mathrm{n}=8000$ 1/min, $\mathrm{ap}_{\mathrm{p}}=1.5 \mathrm{~mm}, \mathrm{ae}=0.6 \mathrm{~mm}, \mathrm{vf}=$ var.

Metrology \& Filtering: Kistler MiniDyn force transducer, $\mathrm{F}_{\mathrm{a}}$ is geometric mean of $\mathrm{F}_{\mathrm{x}}$ and $\mathrm{F}_{\mathrm{y}}$

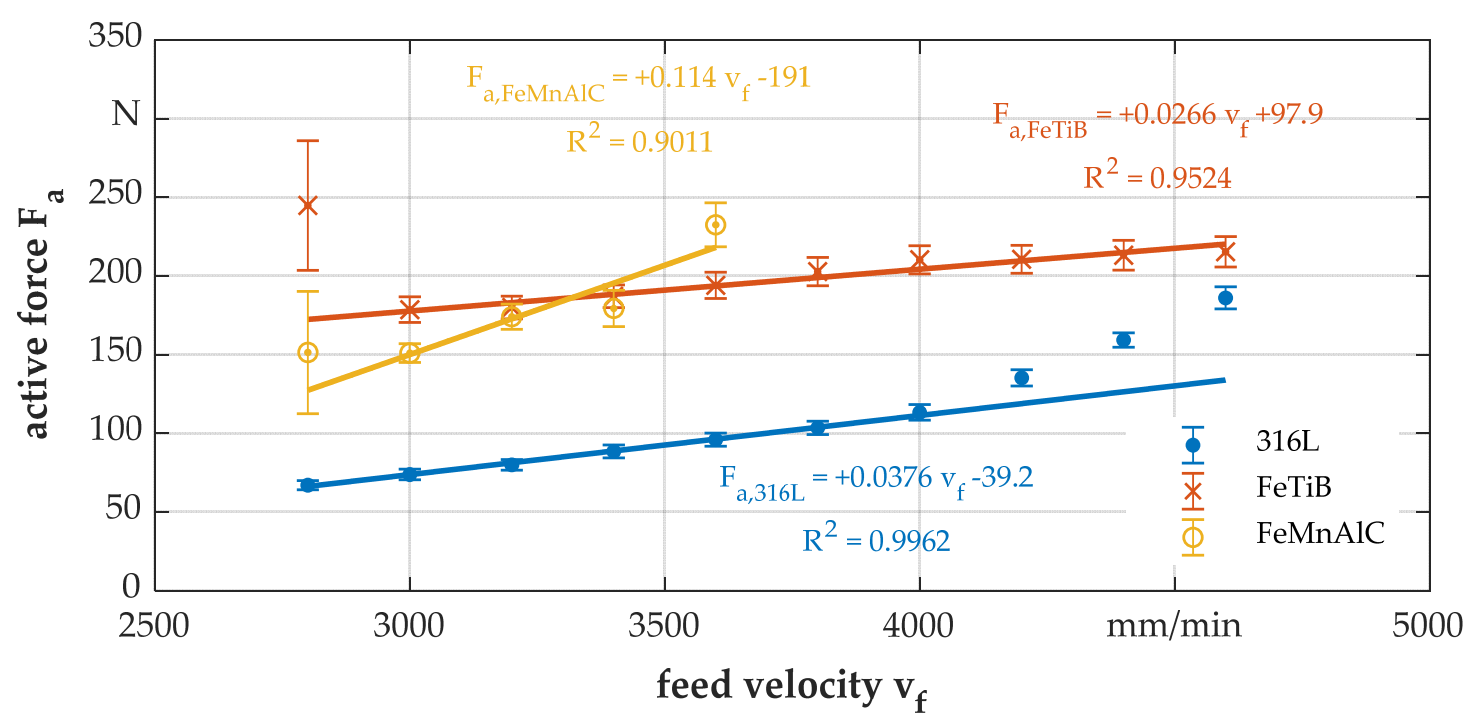

Figure 5. Feed velocity dependent active cutting force; force values are the weighted mean of $\mathrm{F}_{\mathrm{a}}$ for three experiments, error bars indicate the error of the mean as the maximum of the internal (error within each measurement) and external (error across the repetitions) error.

The resulting surface roughness with respect to the feed velocity is assessed via the arithmetic mean height of the surface, using different filter settings. The surface roughness Sa is calculated according to ISO 25178 after applying an S-filter of $10 \mu \mathrm{m}$ and an L-filter of $0.8 \mathrm{~mm}$, while the waviness Wa (technically also "Sa", but Wa is used here for easier differentiation) is determined using an S-filter of $0.8 \mathrm{~mm}$. Average values and standard deviations are calculated across the repetitions for each feed velocity $(n=3)$. The results are shown in Figure 6. The graph shows that the roughness increases with increasing feed velocity for $316 \mathrm{~L}$ and $\mathrm{FeTiB}$, starting from $\mathrm{Sa} \approx 400 \mathrm{~nm}$ to $\mathrm{Sa} \approx 600 \mathrm{~nm}$. Due to the small amount of applicable velocities for FeMnAlC, no definite trend can be determined in this case. The waviness values show a similar trend to the roughness values, but on a much smaller scale $(\mathrm{Wa}<200 \mathrm{~nm})$. In all cases, no fitting operation was found that yielded sufficiently high determination coefficients. Therefore, all values are connected by lines for better readability.

Figure 7 shows the microstructure of all investigated materials after milling with a medium feed rate. The visible grains show the typical deformation of cold-sprayed particles, but no influence of the milling procedure is discernible: all particles are cleanly cut and show no sign of additional plastic deformation. At some locations, particles appear to have been torn from the surface; however, it cannot be clearly stated whether this is the result of the milling process, of the micrograph preparation, or of poor bonding originating in the cold spraying process. 
Process: slot milling of cold sprayed samples

Tool: torodial miller, $\mathrm{t}=6, \mathrm{D}=12 \mathrm{~mm}$, $\mathrm{re}=0.5 \mathrm{~mm}$

Parameters: $\mathrm{n}=80001 / \mathrm{min}$, ap $=1.5 \mathrm{~mm}$, ae $=0.6 \mathrm{~mm}, \mathrm{vf}=$ var.

Metrology \& Filtering: CSI, Sa: S $10 \mu \mathrm{m}+\mathrm{L} 0.8 \mathrm{~mm}$, Wa: S $0.8 \mathrm{~mm}, \mathrm{n}=3$

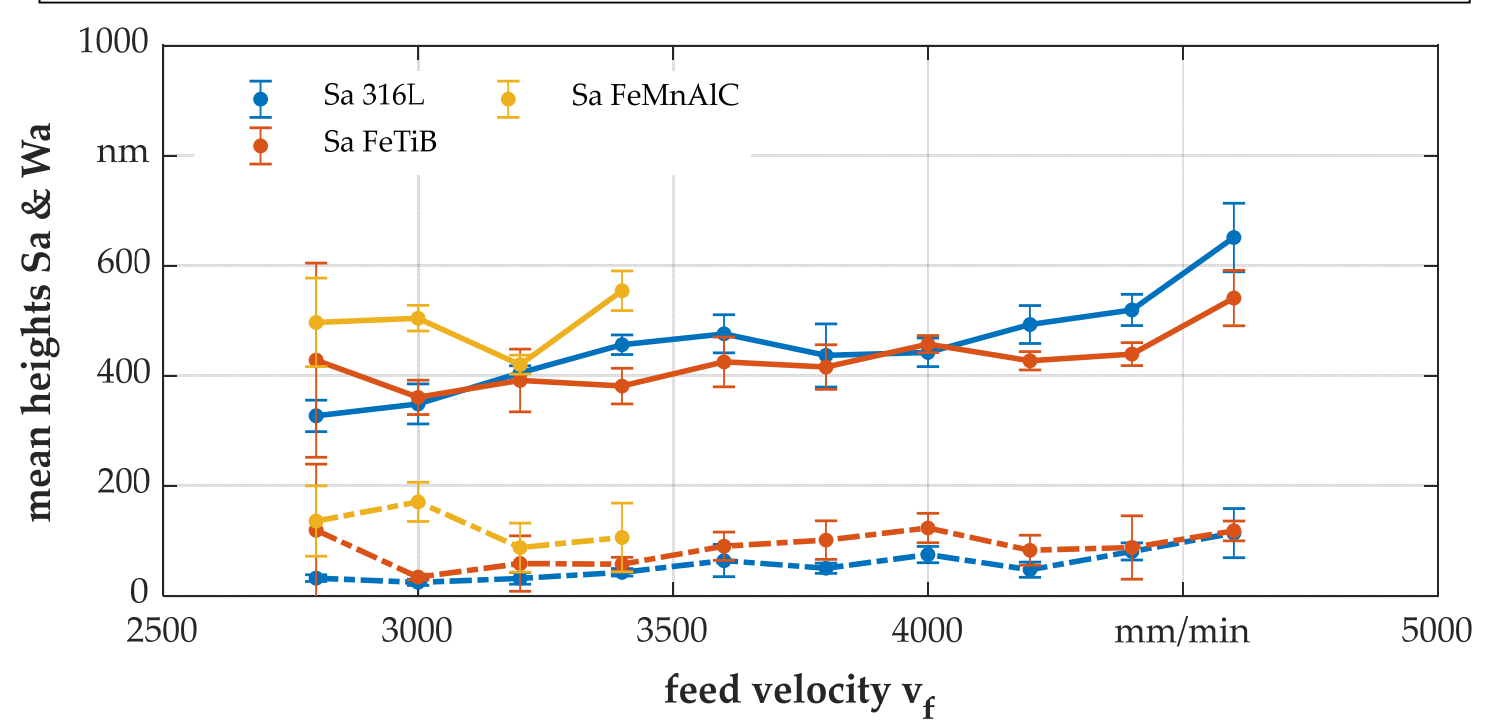

Figure 6. Surface mean heights Sa and Wa versus feed velocity. Error bars indicate standard deviation for repeated measurements on the same part.

a) $316 \mathrm{~L}$

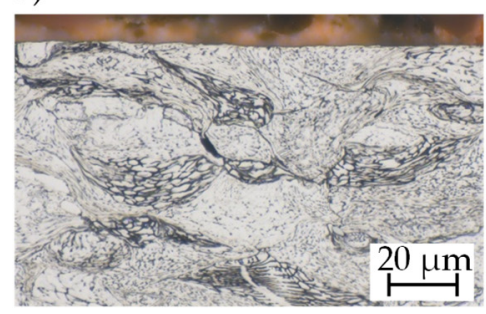

b) FeTiB

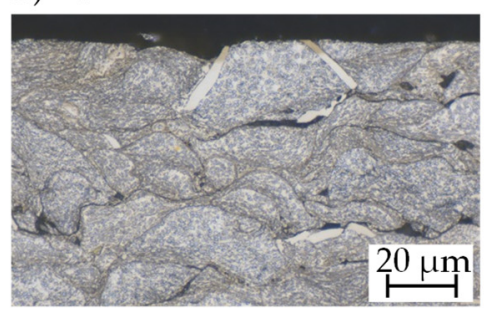

c) FeMnAlC

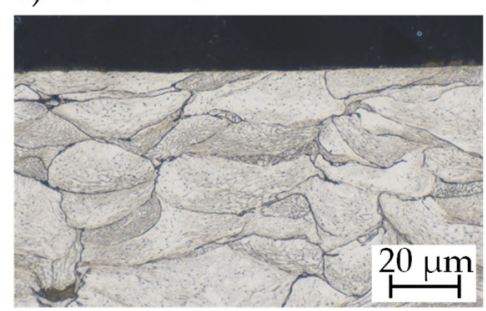

Figure 7. Microstructure after milling: (a) etched $20 \mathrm{~s}$ in $60 \%$ electrolytic $\mathrm{HNO}_{3}(1.5 \mathrm{~V})$; (b,c) etched $15-20 \mathrm{~s}$ in $3 \%$ alcoholic $\mathrm{HNO}_{3}$.

\subsection{Deep Rolling}

Since the samples have a high surface roughness and open porosity after cold gas spraying, the influence of deep rolling without intermediate milling is considered first. Figure 8 shows microscopic images of the sample surface (top view) and false-color images of all materials after deep rolling with varied deep rolling pressure. The surface unaffected by the rolling procedure appears dark in the microscopic images, while the part that has been deformed by the rolling is smoothed and, therefore, reflects more light and appears brighter. For all materials, the amount of deformed surface increases with rising deep rolling pressure, visible by an increasingly "closed" surface. It is assumed that the deformed particles fill the lower areas of the surface and, thereby, fill surface dents and valleys. This is more pronounced for the softer materials 316L and FeMnAlC. Due to the high initial surface roughness as well as the strong height difference of the deformed and non-deformed areas, no roughness parameters could be determined by white light interferometry for the as-sprayed states. 
Material

$316 \mathrm{~L}$

FeTiB

FeMnAlC
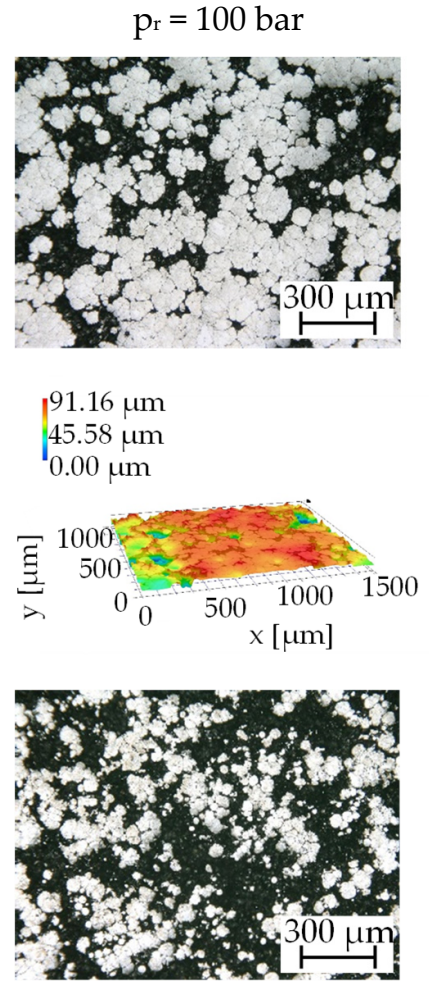

$93.27 \mu \mathrm{m}$

$46.64 \mu \mathrm{m}$

$0.00 \mu \mathrm{m}$
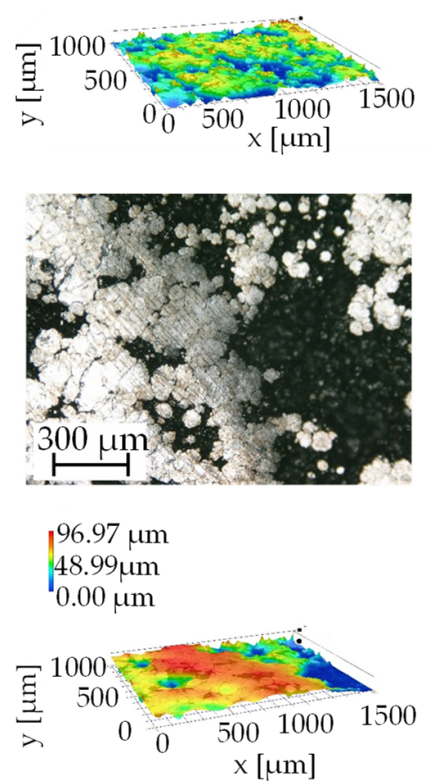

$\mathrm{pr}_{\mathrm{r}}=200 \mathrm{bar}$

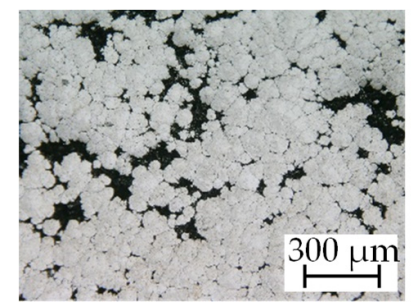

$\mid \begin{aligned} & 90.35 \mu \mathrm{m} \\ & 45.18 \mu \mathrm{m} \\ & 0.00 \mu \mathrm{m}\end{aligned}$
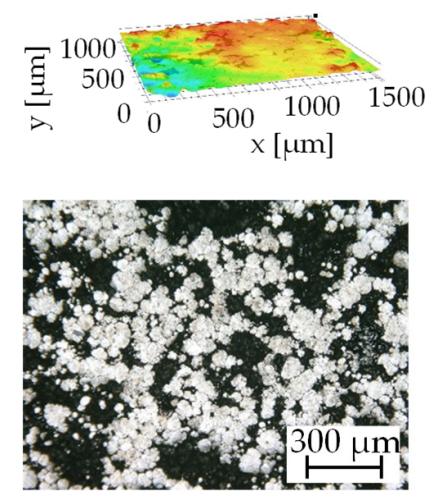

$\mid \begin{aligned} & 80.50 \mu \mathrm{m} \\ & 40.25 \mu \mathrm{m} \\ & 0.00 \mu \mathrm{m}\end{aligned}$
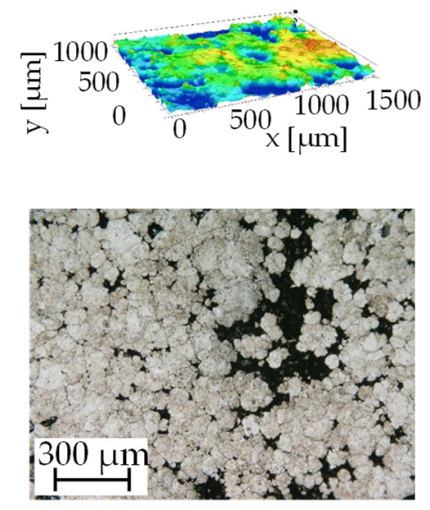

$$
\mid \begin{aligned}
& 82.49 \mu \mathrm{m} \\
& 41.25 \mu \mathrm{m} \\
& 0.00 \mu \mathrm{m}
\end{aligned}
$$



$\mathrm{p}_{\mathrm{r}}=400 \mathrm{bar}$

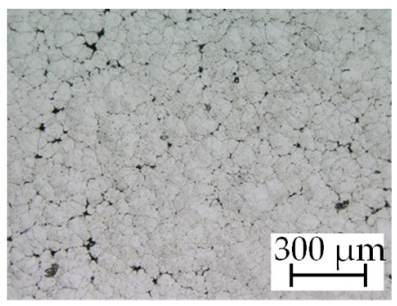

$78.87 \mu \mathrm{m}$

$39.44 \mu \mathrm{m}$

$0.00 \mu \mathrm{m}$
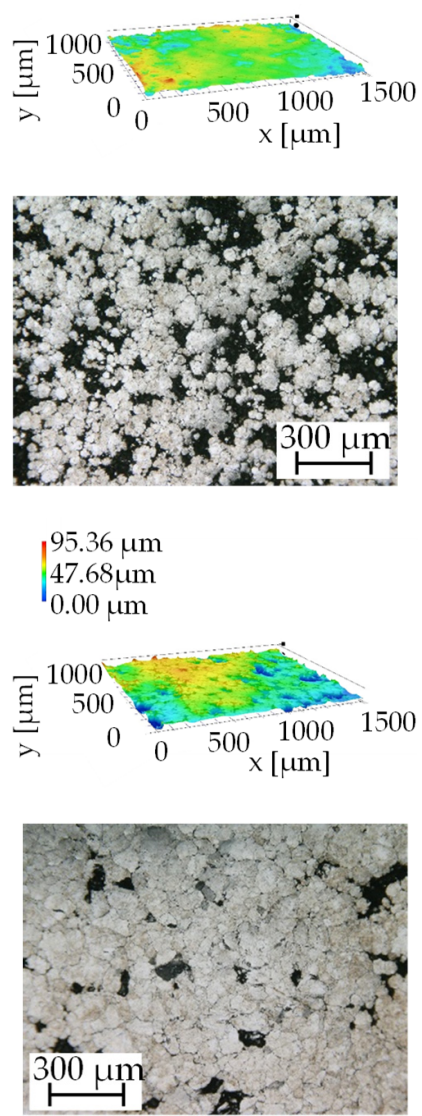

$91.20 \mu \mathrm{m}$

$45.60 \mu \mathrm{m}$

$0.00 \mathrm{~mm}$

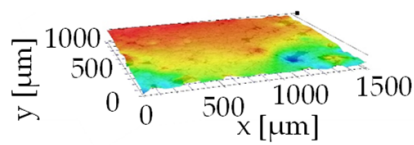

Figure 8. Influencing the surface topography (top view and false-color images) of cold sprayed specimens with the aid of deep rolling.

For the surface with the largest deformation $\left(\mathrm{p}_{\mathrm{r}}=400\right.$ bar), Figure 9 shows the subsurface condition with the aid of micrographs. While for $316 \mathrm{~L}$ and FeTiB, there is no visual difference to the microstructure resulting from the cold gas spraying process, the particles deformed by the deep rolling process are clearly visible for FeMnAlC. Dark boundaries of the near-surface particles indicate cracks and that the single grains are not bonded anymore. 
a) $316 \mathrm{~L}$

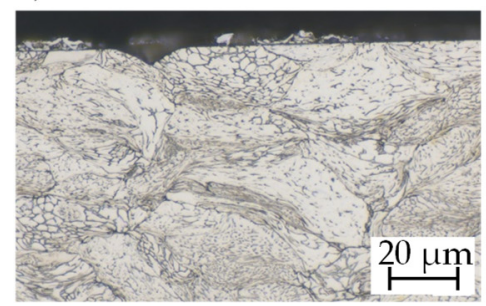

b) FeTiB

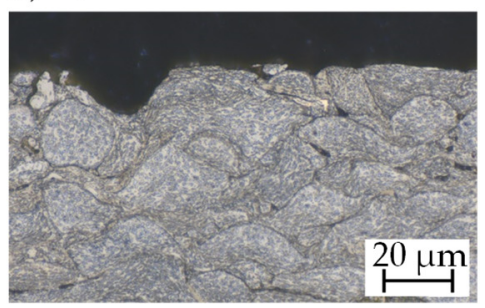

c) FeMnAlC

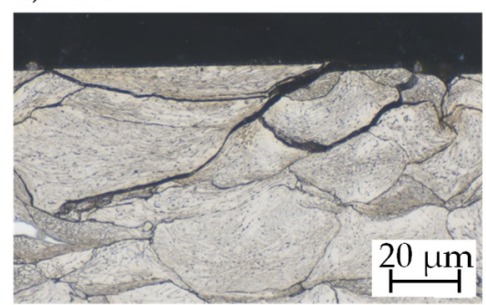

Figure 9. Microstructure after deep rolling with $\mathrm{p}_{\mathrm{r}}=400 \mathrm{bar}$ (no intermediate milling): (a) etched $20 \mathrm{~s}$ in $60 \%$ electrolytic $\mathrm{HNO}_{3}(1.5 \mathrm{~V}) ;(\mathbf{b}, \mathbf{c})$ etched $15-20 \mathrm{~s}$ in 3\% alcoholic $\mathrm{HNO}_{3}$.

In order to evaluate the influence of an increased deep rolling pressure on the subsurface properties of cold gas sprayed materials, further micrographs were generated. Figure 10 shows the microstructure obtained after deep rolling 316L samples with varied deep rolling pressure, with and without intermediate milling, on both substrate materials. There are no optical differences due to the pre-processing strategy, deep-rolling pressure, or the substrate material. The clearly visible deformation lines are distributed over the entire microstructure and result from the more significant deformation of the particles during sample generation.

Processing strategy

Deep rolling with intermediate milling (aluminum substrate)

Deep rolling without intermediate milling (aluminum substrate)

Deep rolling without intermediate milling (steel substrate)

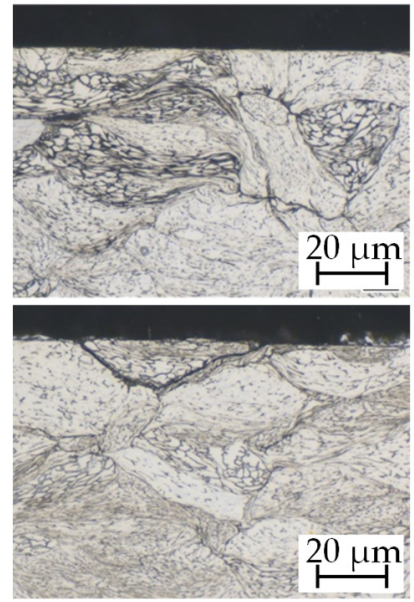

$\mathrm{p}_{\mathrm{r}}=200 \mathrm{bar}$
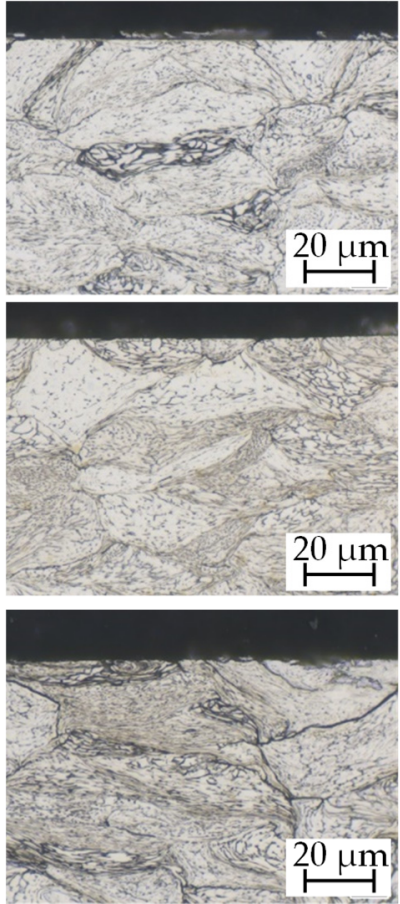

$\mathrm{p}_{\mathrm{r}}=400 \mathrm{bar}$
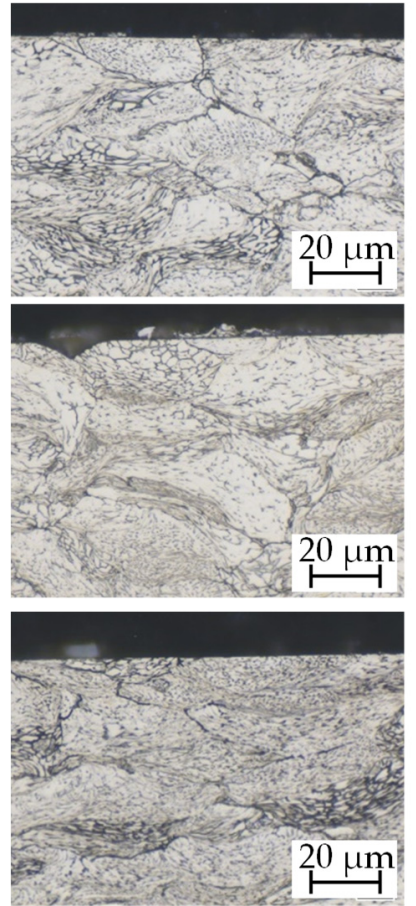

Figure 10. Influence of increasing deep rolling pressure with and without intermediate milling on both substrate materials for 316L (etched $20 \mathrm{~s}$ in $60 \%$ electrolytic $\mathrm{HNO}_{3}(1.5 \mathrm{~V})$ )).

To analyze the extent of the influence on the subsurface properties, hardness measurements were performed on the microsections of selected samples. Since no significant modification of the microstructure is expected or observed using the selected milling parameters, and the high surface roughness of the samples directly after the initial forming makes a comparable measurement difficult, only samples with intermediate milling are considered in the following. 
Figure 11 exemplarily shows the hardness depth profiles determined for 316L (a), FeTiB (b) and FeMnAlC (c) on aluminum substrates. Using a test load of $9.8 \mathrm{~N}$ and taking into account the acceptable indentation distances, it was possible to carry out two measurements in conformity with the standard below the deep rolled areas. The error bars, therefore, represent the minimum and maximum measured values determined for each depth. To investigate the influence of an increased deep rolling pressure, Figure 11a shows the hardness depth profiles for 316L with a varied deep rolling force, as well as directly after the milling process. Prior to deep rolling, the material already exhibits a hardness of about $400 \mathrm{HV} 1$. This is significantly higher than the hardness of the LPBF specimens used for comparison (see: reference values). The variations visible in Figure 11 can be attributed to the microstructure. According to Liu et al., fine grains are formed at the particle-particle as well as particle-substrate interfaces [17], resulting in zones of increased hardness compared to the inner particle (cf. [7]). Applying a deep rolling pressure, regardless of its value, did not result in any visible change in the hardness level. A hardness maximum below the surface, which is characteristic for deep rolling, cannot be detected either. The hardness depth profiles of the materials FeTiB and FeMnAlC determined for a medium deep rolling pressure of 200 bar also show constant hardness levels of about 650 HV1 and 400 HV1, respectively. Since, despite visible plastic deformation, no further increase in hardness is detectable due to the deep rolling process, the latter is presumably incapable of producing further work hardening. Nevertheless, it can be assumed that additional dislocations have been formed. This is confirmed regarding the results of additionally performed EBSD measurements (see Figure 12). Image quality, inverse pole figure, and Kernel Average Misorientation (KAM) show differences between the unaffected reference condition, the condition after sole milling and the condition after milling and deep rolling. While larger areas of low misorientation (blue) are visible with and without milling, the misorientation increases after deep rolling (green). The increased number of differently colored areas occurring in the inverse pole figure after deep rolling further suggests grain refinement as a result of the process. There is no texturing visible.

Process: deep rolling

Tool: HG 6

Parameters: $\mathrm{p}_{\mathrm{r}}=100 ; 200$ and 400 bar

Hardness measurement: HV1 (HV0.5); force: 9.8 N (4.9 N)

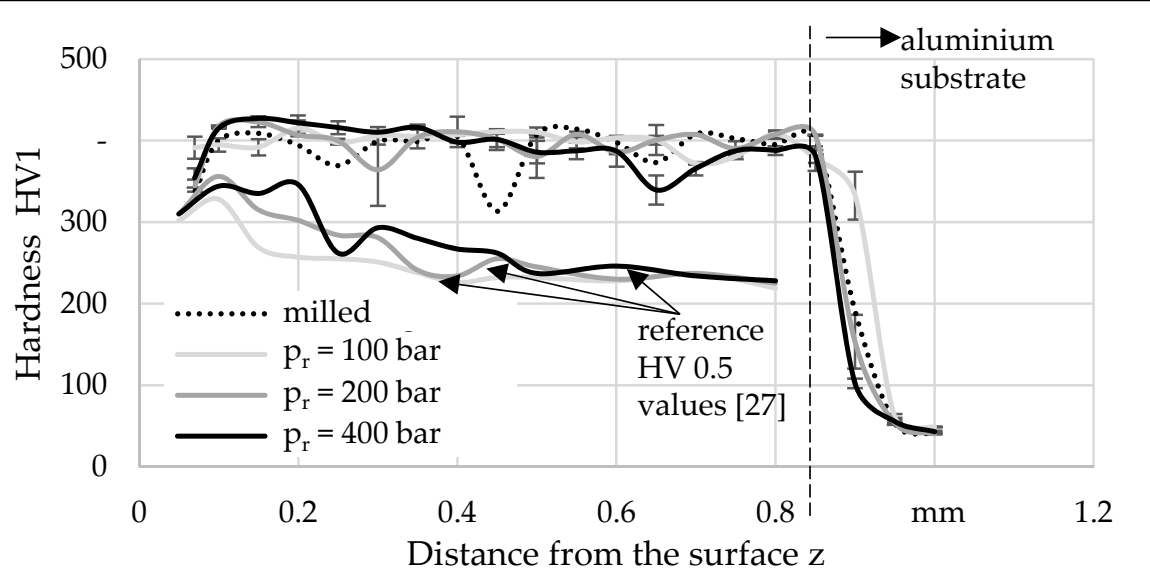

(a)

Figure 11. Cont. 
Process: deep rolling

Tool: HG 6

Parameters: $p_{r}=200$

Hardness measurement: HV1; force: $9.8 \mathrm{~N}$

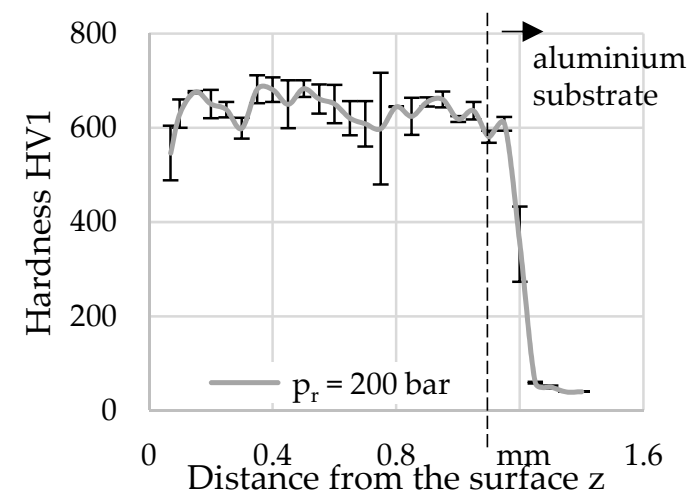

(b)
Process: deep rolling

Tool: HG 6

Parameters: $p_{r}=200$

Hardness measurement: HV1; force: $9.8 \mathrm{~N}$

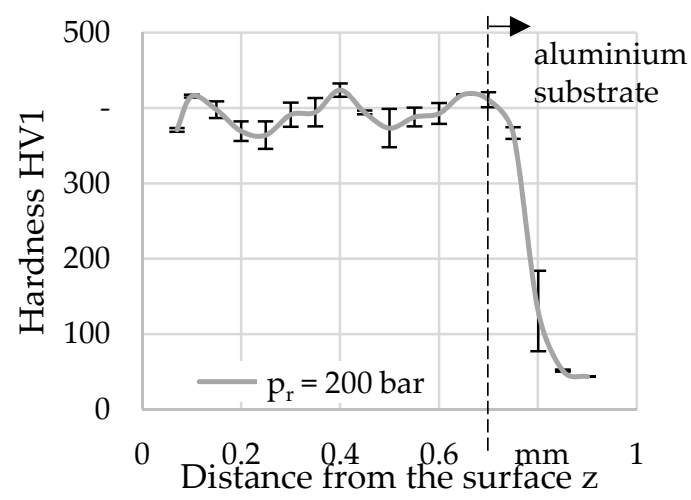

(c)

Figure 11. Hardness depth profiles determined (with intermediate milling) for (a) 316L (varied deep rolling pressure) and for a constant deep rolling pressure of 200 bar for (b) FeTiB and (c) FeMnAlC.

\begin{tabular}{|c|c|c|c|}
\hline & Image quality (IQ) & Inverse pole figure (IPF) & $\begin{array}{l}\text { Kernel Average Misorienta- } \\
\text { tion (KAM) }\end{array}$ \\
\hline $\begin{array}{l}\text { (a) Unaffected ref- } \\
\text { erence condition } \\
\text { (measured at a dis- } \\
\text { tance from the sur- } \\
\text { face of } z=308 \mu \mathrm{m} \text { ) }\end{array}$ & (1) & 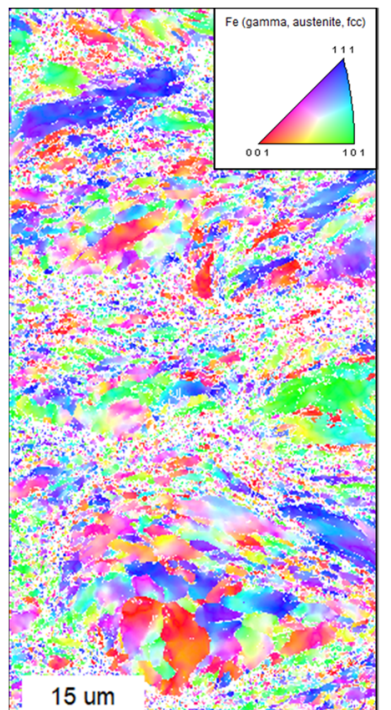 & 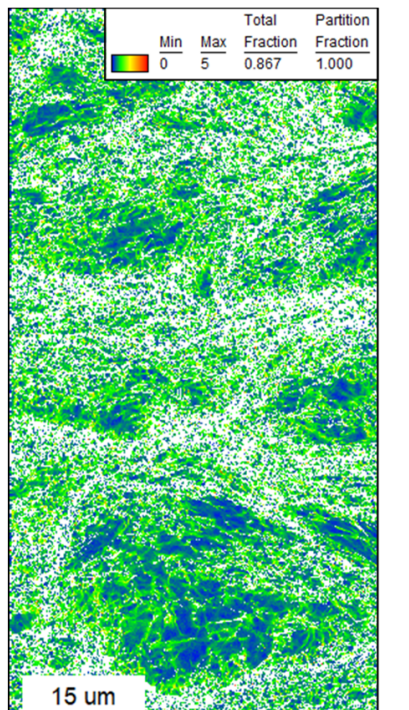 \\
\hline
\end{tabular}

Figure 12. Cont. 


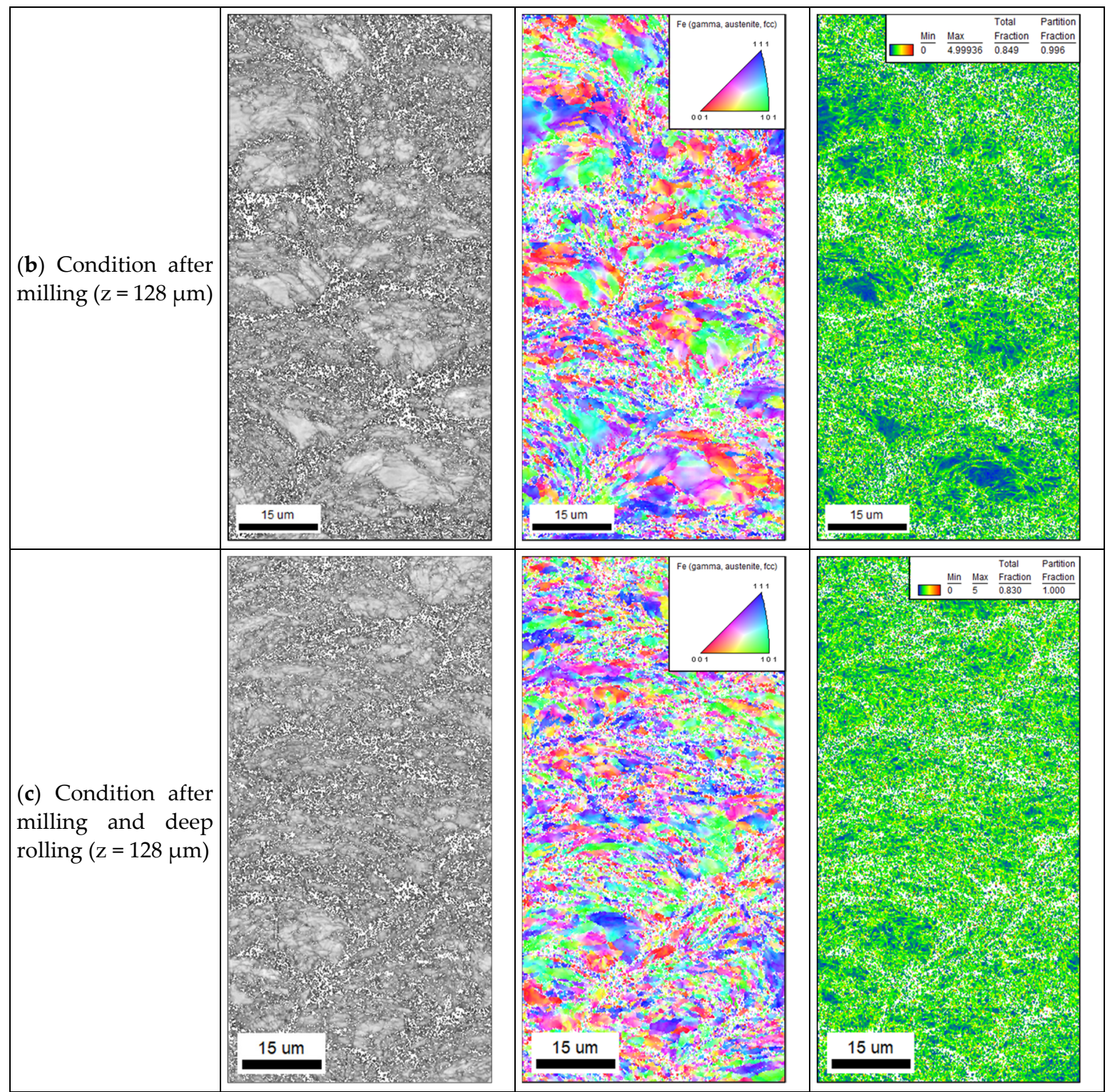

Figure 12. Image quality, inverse pole figure and Kernel Average Misorientation determined by EBSD measurements for (a) an unaffected reference condition, (b) a milled subsurface, and (c) a milled and deep rolled subsurface.

\section{Discussion}

As a result of the forming process, the microstructure exhibits strongly deformed grains after cold gas spraying. In some cases, the original particles can still be recognized. Nevertheless, an evaluation of the particle compression ratio comparable to that of Liu's work was not possible, since a large number of particles of varying size were brought to impact in order to generate the investigated coating (cf. [17]). The severe plastic deformation of the particles is accompanied by a high initial hardness. For example, the material hardness determined for 316L before deep rolling, with values of around $400 \mathrm{HV} 1$, is significantly higher than the value of $240 \mathrm{HV} 0.5$ reported for LPBF samples of the same material in [27].

While at a slow feed velocity of $3000 \mathrm{~mm} / \mathrm{min}$, corresponding to the material hardness, the forces are lowest for 316L, slightly higher for FeMnAlC and highest for FeTiB, no correlation between the resultant cutting force and the material hardness can be determined due to the different increases in cutting force with increasing feed velocity. The strongest increase in force is observed for FeMnAlC and the smallest for FeTiB. Considering the 
surface roughness, the Sa and Wa values for 316L and FeTiB increase comparably with increasing feed velocity despite significantly different hardness levels. Consequently, no correlation between the resulting variables and the material hardness could be determined so far.

Considering the influence of deep rolling, the light microscopic and false-color images of the surfaces after deep rolling already show differences due to hardness. While the surfaces of the softer materials (316L, FeMnAlC) showed increasing deformations after deep rolling with increasing deep rolling pressure, larger undeformed areas can be seen for FeTiB even at a maximum deep rolling pressure of 400 bar. On the basis of the micrographs prepared for a deep rolling pressure of $400 \mathrm{bar}$, fractured/broken out grains can be seen for FeMnAlC. Due to the high surface roughness, it was not possible to determine roughness values for the as-printed and deep-rolled without intermediate milling states by means of white-light interferometry. Consequently, a comparison with the values reported in the literature is not yet possible. For subsequent work, larger machined surface areas will, therefore, enable a tactile roughness measurement.

It can be stated that further plastic deformation of the as-sprayed surfaces occurred as a result of deep rolling. Since work hardening may thereby occur as a result of plastic deformation, comparably to the investigations of Meyer and Wielki [27], an increase in the material hardness below the surface would have been expected (see Figure 11). In contrast to this expectation, no increase in hardness could be determined as a result of the deep rolling process. This can be attributed to the high initial hardness of the material as a result of the forming. However, additional EBSD measurements showed increased misorientation and grain refinement as a result of the rolling process, confirming the hypothesis of formed dislocations, which will be addressed in subsequent studies by further analyses such as a half-width determination.

\section{Conclusions}

In this work, initial insights about the machinability of cold sprayed specimens of various materials could be gained. In both milling and deep rolling, the material properties resulting from the forming process, such as the high material hardness or particle bonding, had an influence on the process forces or the machining result. Nevertheless, no correlations between the resulting variables of both processes and the material properties could be identified so far. In subsequent work, additional analyses such as the determination of half-widths should allow further conclusions to be drawn about the material behavior.

Author Contributions: Investigation, L.S. and N.M.; Supervision, D.M., V.U. and B.K.; Writingoriginal draft, L.S. and N.M.; Writing-review and editing, D.M., V.U. and B.K. All authors have read and agreed to the published version of the manuscript.

Funding: This research received no external funding.

Institutional Review Board Statement: Not applicable.

Informed Consent Statement: Not applicable.

Data Availability Statement: Data is contained within the article. Further raw data is available on request from the corresponding author. It is not publicly available since it is part of an ongoing study.

Acknowledgments: The authors would like to acknowledge the support of Lucas Barcelos Otani (Federal University of São Carlos, formerly Leibniz IWT) who provided the cold gas sprayed samples for this work.

Conflicts of Interest: The authors declare no conflict of interest. 


\section{Abbreviations}

\begin{tabular}{|c|c|}
\hline$a_{e}$ & $(\mathrm{~mm})$ \\
\hline$a_{p}$ & $(\mathrm{~mm})$ \\
\hline$d_{b}$ & $(\mathrm{~mm})$ \\
\hline $\mathrm{F}_{\mathrm{a}}$ & $(\mathrm{N})$ \\
\hline $\mathrm{F}_{\mathrm{r}}, \mathrm{F}_{\mathrm{r} \text {, theor. }}$ & $(\mathrm{N})$ \\
\hline $\mathrm{F}_{\mathrm{x}}, \mathrm{F}_{\mathrm{y}}$ & $(\mathrm{N})$ \\
\hline$f_{\text {peak }}$ & $(\mathrm{Hz})$ \\
\hline $\mathrm{n}$ & $\left(\min ^{-1}\right)$ \\
\hline $\mathrm{pr}_{\mathrm{r}}$ & (bar) \\
\hline $\mathrm{R}^{2}$ & $(-)$ \\
\hline $\mathrm{Ra}, \mathrm{Rz}$ & $(\mu \mathrm{m})$ \\
\hline $\mathrm{Sa}, \mathrm{Sz}$ & $(\mu \mathrm{m})$ \\
\hline $\mathrm{S}_{\mathrm{Fa}}$ & $(\mathrm{N})$ \\
\hline $\mathrm{s}_{\mathrm{O}}$ & $(\mathrm{mm})$ \\
\hline $\mathrm{v}_{\mathrm{C}}$ & $\left(\mathrm{m} \cdot \min ^{-1}\right)$ \\
\hline$v_{f}$ & $(\mathrm{~mm} / \mathrm{min})$ \\
\hline $\mathrm{v}_{\mathrm{r}}$ & $(\mathrm{mm} / \mathrm{min})$ \\
\hline Wa & $(\mu \mathrm{m})$ \\
\hline$x, y, z$ & $(\mu \mathrm{m})$ or $(\mathrm{mm})$ \\
\hline$\sigma$ & (various) \\
\hline
\end{tabular}

width of cut

depth of cut

tool diameter

active force

deep rolling force, theoretical deep rolling force

$\mathrm{X}$ - and Y-force components

frequency

spindle speed

deep rolling pressure

determination coefficient

surface roughness (profile-based)

surface roughness (areal)

standard deviation of the mean of $\mathrm{F}_{\mathrm{a}}$

step over

cutting speed

feed velocity

rolling speed $v_{r}$

waviness

$\sigma \quad$ (various)

distance in different coordinate directions; $z$ : distance from the surface standard deviation

\section{References}

1. Schmidt, M.; Merklein, M.; Bourell, D.; Dimitrov, D.; Hausotte, T.; Wegener, K.; Overmeyer, L.; Vollertsen, F.; Levy, G.N. Laser based additive manufacturing in industry and academia. CIRP Ann. 2017, 66, 561-583. [CrossRef]

2. Thompson, M.K.; Moroni, G.; Vaneker, T.; Fadel, G.; Campbell, R.I.; Gibson, I.; Bernard, A.; Schulz, J.; Graf, P.; Ahuja, B.; et al. Design for Additive Manufacturing: Trends, opportunities, considerations, and constraints. CIRP Ann. 2016, 65, 737-760. [CrossRef]

3. Bourell, D.; Kruth, J.P.; Leu, M.; Levy, G.; Rosen, D.; Beese, A.M.; Clare, A. Materials for additive manufacturing. CIRP Ann. 2017, 66, 659-681. [CrossRef]

4. Sampath, S.; Jiang, X.Y.; Matejicek, J.; Prchlik, L.; Kulkarni, A.; Vaidya, A. Role of thermal spray processing method on the microstructure, residual stress and properties of coatings: An integrated study for Ni-5 wt.\%Al bond coats. Mater. Sci. Eng. A 2004, 364, 216-231. [CrossRef]

5. Villa, M.; Dosta, S.; Guilemany, J.M. Optimization of 316L stainless steel coatings on light alloys using Cold Gas Spray. Surf. Coat. Technol. 2013, 235, 220-225. [CrossRef]

6. Coddet, P.; Verdy, C.; Coddet, C.; Debray, F.; Lecouturier, F. Mechanical properties of thick 304L stainless steel deposits processed by He cold spray. Surf. Coat. Technol. 2015, 277, 74-80. [CrossRef]

7. Rokni, M.R.; Nutt, S.R.; Widener, C.A.; Champagne, V.K.; Hrabe, R.H. Review of Relationship between Particle Deformation, Coating Microstructure, and Properties in High-Pressure Cold Spray. J. Spray Technol. 2017, 26, 1308-1355. [CrossRef]

8. Grujicic, M.; Zhao, C.L.; DeRosset, W.S.; Helfritch, D. Adiabatic shear instability based mechanism for particles/substrate bonding in the cold-gas dynamic-spray process. Mater. Des. 2004, 25, 681-688. [CrossRef]

9. van Steenkiste, T.; Smith, J.R. Evaluation of Coatings Produced via Kinetic and Cold Spray Processes. J. Spray Technol. 2004, 13, 274-282. [CrossRef]

10. Marx, S.; Paul, A.; Köhler, A.; Hüttl, G. Cold Spraying: Innovative Layers for New Applications. J. Spray Technol. 2006, 15, 177-183. [CrossRef]

11. Yin, S.; Cizek, J.; Cupera, J.; Hassani, M.; Luo, X.; Jenkins, R.; Xie, Y.; Li, W.; Lupoi, R. Formation conditions of vortex-like intermixing interfaces in cold spray. Mater. Des. 2021, 200, 109444. [CrossRef]

12. Papyrin, A. Cold Spray Technology, 1st ed.; Elsevier: Amsterdam, The Netherlands, 2007; ISBN 9780080451558.

13. Gärtner, F.; Stoltenhoff, T.; Schmidt, T.; Kreye, H. The Cold Spray Process and Its Potential for Industrial Applications. J. Spray Technol. 2006, 15, 223-232. [CrossRef]

14. Irissou, E.; Legoux, J.-G.; Ryabinin, A.N.; Jodoin, B.; Moreau, C. Review on Cold Spray Process and Technology: Part I—Intellectual Property. J. Spray Technol. 2008, 17, 495-516. [CrossRef]

15. Champagne, V.K. The Cold Spray Materials Deposition Process: Fundamentals and Applications; Woodhead Publishing: Sawston, UK, 2007; ISBN 9781420066708.

16. AL-Mangour, B.; Mongrain, R.; Irissou, E.; Yue, S. Improving the strength and corrosion resistance of 316L stainless steel for biomedical applications using cold spray. Surf. Coat. Technol. 2013, 216, 297-307. [CrossRef]

17. Liu, T.; Leazer, J.D.; Brewer, L.N. Particle deformation and microstructure evolution during cold spray of individual Al-Cu alloy powder particles. Acta Mater. 2019, 168, 13-23. [CrossRef] 
18. Ogawa, K.; Ito, K.; Ichimura, K.; Ichikawa, Y.; Ohno, S.; Onda, N. Characterization of Low-Pressure Cold-Sprayed Aluminum Coatings. J. Spray Technol. 2008, 17, 728-735. [CrossRef]

19. Schulze, V.; Bleicher, F.; Groche, P.; Guo, Y.B.; Pyun, Y.S. Surface modification by machine hammer peening and burnishing. CIRP Ann. 2016, 65, 809-832. [CrossRef]

20. Wohlfahrt, H. The Influence of Peening Conditions on the Resulting Distribution of Residual Stress. In Proceedings of the Second International Conference on Shot Peening, Chicago, IL, USA, 14-17 May 1984; pp. 316-331.

21. Bleicher, F.; Lechner, C.; Habersohn, C.; Kozeschnik, E.; Adjassoho, B.; Kaminski, H. Mechanism of surface modification using machine hammer peening technology. CIRP Ann. Manuf. Technol. 2012, 1, 375-378. [CrossRef]

22. Breidenstein, B.; Brenne, F.; Wu, L.; Niendorf, T.; Denkena, B. Effect of Post-Process Machining on Surface Properties of Additively Manufactured H13 Tool Steel. HTM J. Heat Treat. Mater. 2018, 73, 173-186. [CrossRef]

23. Kloos, K.H.; Adelmann, J. Schwingfestigkeitssteigerung durch Festwalzen. Mater. Werkst. 1988, 19, 15-23. [CrossRef]

24. Broszeit, E. Grundlagen der Schwingfestigkeitssteigerung durch Fest- und Glattwalzen. Mater. Werkst. 1984, 15, 416-420. [CrossRef]

25. Breidenstein, B.; Denkena, B.; Meyer, K.; Prasanthan, V. Influence of subsurface properties on the application behavior of hybrid components. Procedia CIRP 2020, 87, 302-308. [CrossRef]

26. Wielki, N. Potential of deep rolling as a finishing process directly after SLM to generate beneficial surface and subsurface properties: Euspen Conference Proceedings Bilbao June 2019. In Proceedings of the Euspen' 19th International Conference \& Exhibition, Bilbao, Spain, 3-7 June 2019; pp. 370-371.

27. Meyer, D.; Wielki, N. Internal reinforced domains by intermediate deep rolling in additive manufacturing. CIRP Ann. 2019. [CrossRef]

28. Sandvik. OSPREY ®316L for Additive Manufacturing: Datasheet. Available online: https://www.metalpowder.sandvik/ siteassets / metal-powder/datasheets/osprey-3161-am-austenitic-stainless-steels.pdf (accessed on 21 October 2020).

29. Springer, H.; Baron, C.; Mostaghimi, F.; Poveleit, J.; Mädler, L.; Uhlenwinkel, V. Additive manufacturing of high modulus steels: New possibilities for lightweight design. Addit. Manuf. 2020, 32, 101033. [CrossRef] 